\title{
Vasopressin, from Regulator to Disease Predictor for Diabetes and Cardiometabolic Risk
}

\author{
Olle Melander
}

Department of Clinical Sciences, Lund University and Department of Internal Medicine, Skåne University Hospital, Malmö, Sweden

\section{Key Words}

Vasopressin · Hydration · Diabetes mellitus - Copeptin .

Cardiovascular disease

\begin{abstract}
Background: Type 2 diabetes and its cardiovascular disease complications are the major public health threats of our century. Although physical activity and dietary changes are the cornerstones in prevention of diabetes, their broad implementation is not elementary and other complementary lifestyle regimens are needed. Summary: Vasopressin (VP) is the main regulator of body water homeostasis, and at insufficient water intake, normal plasma osmolality can be maintained by increased pituitary VP secretion through VP-2 receptor mediated renal water reabsorption. During the last 6 years several independent studies have shown that high circulating VP, measured by the stable VP marker copeptin, predicts development of type 2 diabetes as well as the metabolic syndrome, cardiovascular disease and premature mortality. Interestingly, VP stimulates adrenocorticotrophic hormone, and as a consequence cortisol secretion, through pituitary VP-1B receptors, which could explain why the $25 \%$ of the middle-aged population with high circulating VP have a mild Cushing's syndrome-like phenotype. In rats, high VP results in deterioration of glucose tolerance whereas low VP,
\end{abstract}

obtained by high water intake, ameliorates the VP associated dysmetabolic state, suggesting that the relationship between high VP and risk of diabetes and cardiometabolic disease in humans may be causal and reversible by increasing water intake. Key Messages: With the emerging evidence that high VP, which is present in $25 \%$ of the population, is an independent risk factor for diabetes and cardiometabolic disease, VP reduction through water supplementation appears as an attractive candidate intervention to prevent diabetes and its cardiovascular complications.

(c) 2016 The Author(s)

Published by S. Karger AG, Basel

\section{The Importance of Prevention of Type 2 DM in Order to Reduce the Burden of Cardiovascular Disease}

The number of patients with type 2 diabetes in Europe and the world increases constantly and represents a major threat to global cardiovascular health, as a potent risk factor for cardiovascular morbidity and mortality $[1,2]$. Importantly, the excess cardiovascular risk seems to start at non-diabetic levels of glycemia long before clinical diagnosis of type 2 diabetes [3]. Apart from disturbed glucose metabolism, both patients with overt type 2 diabetes and healthy people with elevated risk of diabetes development

\section{KARGER \\ E-Mail karger@karger.com www.karger.com/anm}

\section{() 2016 The Author(s) \\ Published by S. Karger AG, Basel 0250-6807/16/0686-0024\$39.50/0}

This article is licensed under the Creative Commons AttributionNonCommercial-NoDerivatives 4.0 International License (CC BYNC-ND) (http://www.karger.com/Services/OpenAccessLicense). Usage and distribution for commercial purposes as well as any distribution of modified material requires written permission. 
are typically characterized by insulin resistance and clusters of other cardiovascular risk factors (e.g., obesity, in particular abdominal obesity with excess hepatic fat or liver steatosis, insulin resistance, hypertension, dyslipidemia, microalbuminuria and chronic inflammation). This diabetes and pre-diabetes related clustering of risk factors, sometimes referred to as 'the metabolic syndrome', puts affected individuals at extreme cardiovascular risk [4-6].

Intriguingly, many trials aimed at reducing blood glucose in patients with manifest type 2 diabetes, in order to reduce the marked excess risk of cardiovascular disease and death that these patients suffer from, have failed to do so [7-9]. One likely explanation is that treatment is initiated too late; this assumes that, when type 2 diabetes is established and diagnosed, the atherosclerotic burden is so advanced that it is difficult to reverse by blood glucose lowering therapies. This emphasizes the need for diabetes prevention in order to avoid its macrovascular complications. Although dietary changes and physical activity are the cornerstones in the prevention of obesity and diabetes, it is not elementary to broadly implement these preventive interventions, and they have not been able to satisfactorily reduce obesity and diabetes rates. Thus, new complementary preventive easy-to-implement lifestyle interventions need to be discovered.

\section{The Vasopressin System}

Vasopressin (VP), also named antidiuretic hormone, is released from the posterior pituitary gland with the main physiological role of maintaining constant plasma osmolality during altered hydration states. When water intake is low, increased pituitary VP secretion prevents hyper-osmolality by enhancing renal water reabsorption and leading to urine concentration through VP stimulation of the VP-2 receptor in the renal collecting ducts. At high levels of water intake, VP secretion is suppressed, leading to low circulating VP concentration and low urine osmolality [10]. Severe hypotension is another stimulus for VP secretion, as observed in patients with septic shock involving VP stimulation of the VP$1 \mathrm{~A}$ receptor (V1AR), which promotes vasoconstriction [11]. The VP drive is also enhanced in certain diseases state such as myocardial infarction, chronic kidney disease and heart failure [12-14]. However, during normal conditions, the main determinant of circulating VP level is the loss or gain of body water (i.e., hydration status).

VP, from Regulator to Disease Predictor for Diabetes and Cardiometabolic Risk

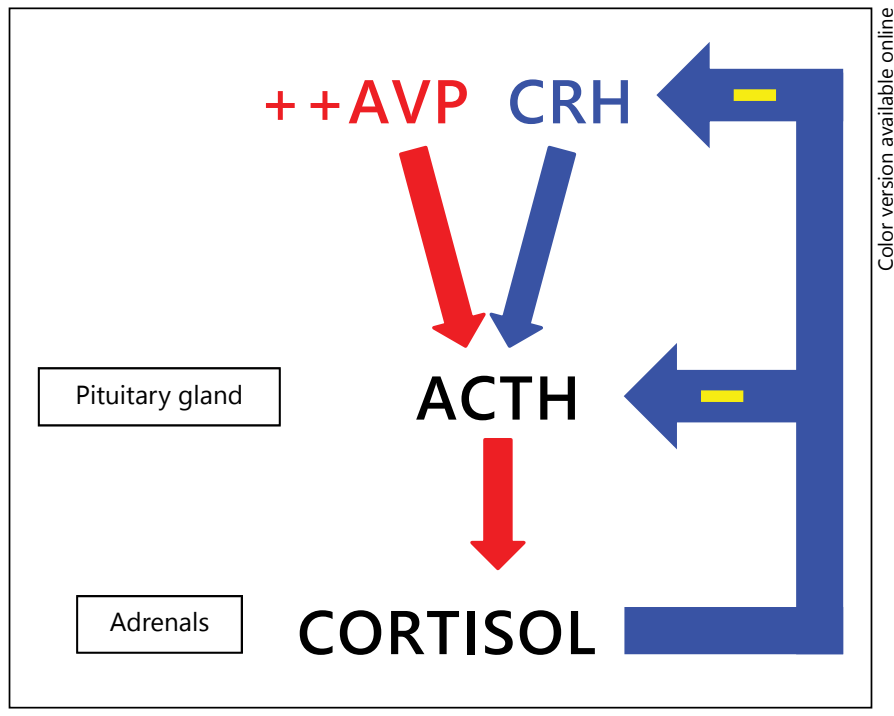

Fig. 1. Arginine VP (AVP) stimulates ACTH-cortisol secretion through stimulation of the pituitary V1BR. Unlike the CRHACTH-cortisol axis, AVP stimulated ACTH/cortisol secretion lacks negative feedback control.

Measuring VP in plasma is cumbersome, partly due to its short half-life in plasma and ex vivo instability $[15,16]$, which led to the development of an assay targeting a stable C-terminal fragment of the VP precursor hormone copeptin. Copeptin is released in equimolar amounts with, and thus correlates well with, VP [13]. Due to its stability in vivo and ex vivo, it has been proposed to be a better marker of VP secretion than measurement of the mature hormone itself [16].

\section{High Levels of VP: Can Diabetes and Cardiometabolic Disease Be Circumvented by Drinking More Water?}

Adrenal hyper-secretion of cortisol, as a result of autonomous cortisol producing adrenal adenomas or adrenocorticotrophic hormone (ACTH) producing pituitary adenomas, causes Cushing's syndrome [17]. The phenotype of Cushing's syndrome is an extreme form of the metabolic syndrome including abdominal obesity, hypertension and dyslipidemia; most of these patients develop diabetes and die from cardiovascular disease. In normal subjects, elevation of cortisol is counterbalanced by a reduction of corticotrophin releasing hormone $(\mathrm{CRH})$ and ACTH, which normalizes cortisol secretion in a steady state, via a negative feedback loop (fig. 1, blue arrows). Interestingly, ACTH secretion can also be stimulated by VP, through stimulation of the pituitary VP-1B receptor

Ann Nutr Metab 2016;68(suppl 2):24-28 DOI: $10.1159 / 000446201$ 
Table 1. New-onset diabetes in relation to quartiles of baseline plasma copeptin concentration

\begin{tabular}{|c|c|c|c|c|}
\hline \multirow[t]{2}{*}{ Dependent variable } & \multicolumn{3}{|l|}{ OR (95\% CI) } & \multirow{2}{*}{$\begin{array}{l}\mathrm{p} \text { (test for } \\
\text { linear trend) }\end{array}$} \\
\hline & $\begin{array}{l}\mathrm{Q} 2_{\text {copeptin }} \text { Vs. } \\
\mathrm{Q} 1_{\text {copeptin }}\end{array}$ & $\begin{array}{l}\text { Q3 } 3_{\text {copeptin Vs. }} \\
\mathrm{Q} 1_{\text {copeptin }}\end{array}$ & $\begin{array}{l}\text { Q4 } 4_{\text {copeptin }} \text { Vs. } \\
\text { Q1 } 1_{\text {copeptin }}\end{array}$ & \\
\hline \multicolumn{5}{|c|}{ Incident diabetes among non-DM* } \\
\hline Crude & $1.28(0.76-2.15)$ & $1.94(1.19-3.14)$ & $2.64(1.66-4.19)$ & $<0.001$ \\
\hline Adjusted ${ }^{\ddagger}$ & $1.37(0.78-2.39)$ & $1.79(1.06-3.05)$ & $2.09(1.23-3.56)$ & 0.004 \\
\hline \multicolumn{5}{|c|}{ Incident diabetes among non-IFG ${ }^{\dagger}$} \\
\hline Crude & $1.85(0.81-4.20)$ & $2.12(0.95-4.73)$ & $4.56(2.18-9.52)$ & $<0.001$ \\
\hline Adjusted $^{\ddagger}$ & $1.80(0.78-4.16)$ & $1.92(0.84-4.38)$ & $3.48(1.58-7.65)$ & 0.001 \\
\hline
\end{tabular}

IFG = Impaired fasting glucose; FBG = fasting blood glucose.

* Subjects who developed diabetes during follow-up $(\mathrm{n}=174)$ among all subjects without diabetes at baseline $(\mathrm{n}=4,377)$.

† Subjects who developed diabetes during follow-up $(\mathrm{n}=79)$ among all subjects without impaired fasting glucose at baseline $(n=3,702)$.

‡ Adjusted for age, sex, high-density lipoprotein, triglycerides, blood pressure, antihypertensive treatment, body mass index, waist, waist/hip ratio, cystatin C, C-reactive protein and prevalent cardiovascular disease, smoking, family history of diabetes, low-density lipoprotein, FBG and fasting insulin.

(V1BR); this mechanism results in hyper-secretion of cortisol [18-20]. Importantly, VP-induced hyper-secretion of ACTH and cortisol does not have a negative feedback loop, and a high concentration of VP can thus result in a vicious circle, a Cushing's syndrome-like phenotype, metabolic syndrome and high risk of diabetes development (fig. 1, red arrows). In addition to these pituitary effects, VP is implicated in glucose homeostasis through regulation of insulin and glucagon via stimulation of pancreatic V1BR; VP also promotes hepatic glycogenolysis and gluconeogenesis via stimulation of the V1AR [2123].

We showed in 2010 that fasting plasma concentration of VP, measured by copeptin, strongly predicted new-onset diabetes independently of all other major diabetes risk factors [24] (table 1), a finding that was replicated in subsequent large prospective population-based studies [25, $26]$. In the population with normal fasting glucose, subjects in the top quartile of copeptin (i.e., $25 \%$ of the population, corresponding to plasma concentration of copeptin of $>6.1 \mathrm{pmol} / \mathrm{l}$ in women and $>10.7 \mathrm{pmol} / \mathrm{l}$ in men) had a 3.5-fold multivariate adjusted increased risk of diabetes mellitus (DM) development, compared to subjects in the lowest quartile of plasma copeptin [24] (table 1). It is remarkable that (a) a high plasma copeptin concentration is predictive of new-onset DM development independent of all diabetes risk factors, including the level of blood glucose at baseline and (b) the effect size associated with high copeptin in relation to diabetes risk is large and comparable to the diabetes risk associated with obesity $[24,27]$. Interestingly, the phenotypic similarity between subjects who have high circulating copeptin concentrations and Cushing's syndrome patients is not limited to the fact that both conditions are accompanied by a high risk of developing DM. We and other research groups found that subjects with high VP concentration are more likely to suffer from all components of the metabolic syndrome including abdominal obesity, insulin resistance, hypertension, chronic inflammation and microalbuminuria $[24,28-30]$. Thus, the $25 \%$ of the population with the highest copeptin concentrations, reflecting a high VP drive, have a phenotype which resembles a mild form of Cushing's syndrome, putting them at high risk of not only type 2 diabetes but the entire metabolic syndrome. Furthermore, we and other researchers have shown that high copeptin is an independent risk factor for cardiovascular disease and premature mortality and that this risk seems to be especially pronounced in patients with DM [31-33]. Although these studies cannot prove causality, they collectively suggest that elevation of VP concentration is linked to risk of developing DM and the metabolic syndrome, followed by increased risk of cardiovascular disease and premature death [24-26, 28-33].

Assuming that the statistically independent relationship between high VP in healthy subjects and risk of future development of DM, metabolic syndrome and cardiovascular morbidity and mortality is indeed causal, inhibition of VP secretion emerges as a novel attractive 
strategy to prevent diabetes and its associated cardiovascular sequels. In subjects without severe hypotension, chronic kidney disease, heart failure or acute myocardial infarction, the most likely cause of high circulating VP is insufficient water intake, as this stimulates VP secretion and renal water reabsorption in order to maintain constant plasma osmolality; conversely, increased water intake inhibits VP secretion [10, 34]. In light of this, increasing water intake appears as the prime candidate intervention to reduce the risk of DM, metabolic syndrome and cardiovascular morbidity and mortality linked to having a high level of circulating VP. In addition, increasing water intake is safe and appears easy-to-implement given its broad availability.

Evidence from both observational studies and intervention trials suggests that high water intake may protect humans from obesity, diabetes and cardiovascular disease [35-38]. Interestingly, epidemiological studies of water intake show that as much as $50 \%$ of the European population has a lower daily water intake than that recommended by the European Food Safety Authority [39]. Furthermore, a causal relationship between level of water intake, VP and cardiometabolic disease risk was recently supported by studies in animals. Our research team found that glucose tolerance was reduced when rats were chronically exposed to high VP; but when rats were put on high water intake, leading to low levels of VP, insulin resistance and hepatic fat accumulation (i.e., 2 hallmarks of the metabolic syndrome) were markedly ameliorated [40].
In summary and conclusion, during the last 6 years, a large number of studies have established high circulating level of VP as a novel risk factor for the development of diabetes, metabolic syndrome and cardiovascular morbidity and mortality. The most likely cause of this relationship is insufficient water intake leading to enhanced VP secretion which, in turn, leads to hyper-secretion of ACTH and cortisol and results in a Cushing syndromelike phenotype. A causal relationship between high VP and high cardiometabolic risk, as well as a favorable effect, achieved by VP reduction with improved hydration status, is supported by studies in rodents. Because $25 \%$ of the middle-aged population of Malmö, Sweden have a high plasma VP level, which is linked to marked elevation in the risk of 2 great public health problems of our century (i.e., diabetes and cardiometabolic disease), hydration-induced reduction of VP appears to be a broadly applicable, safe, cost-effective and easy-to-implement primary preventive intervention that should be evaluated in future large randomized controlled clinical trials. Missing the opportunity to gain a new life style regimen in the fight against diabetes and cardiometabolic disease would be unethical.

\section{Disclosure Statement}

O. Melander has received lecture honoraria from Danone Research.

\section{References}

1 Laakso M: Hyperglycemia and cardiovascular disease in type 2 diabetes. Diabetes 1999;48: 937-942.

2 Zimmet P, Alberti KG, Shaw J: Global and societal implications of the diabetes epidemic. Nature 2001;414:782-787.

3 Coutinho M, Gerstein HC, Wang Y, Yusuf S: The relationship between glucose and incident cardiovascular events. A metaregression analysis of published data from 20 studies of 95,783 individuals followed for 12.4 years. Diabetes Care 1999;22:233-240.

4 Hauner $\mathrm{H}$ : Insulin resistance and the metabolic syndrome - a challenge of the new millennium. Eur J Clin Nutr 2002;56(suppl 1): S25-S29.

5 Reaven GM: Banting lecture 1988. Role of insulin resistance in human disease. Diabetes 1988;37:1595-1607.

6 Reaven GM: The role of insulin resistance and hyperinsulinemia in coronary heart disease. Metabolism 1992;41(5 suppl 1):16-19.
7 Patel A, MacMahon S, Chalmers J, Neal B, Billot L, et al; ADVANCE Collaborative Group: Intensive blood glucose control and vascular outcomes in patients with type 2 diabetes. $\mathrm{N}$ Engl J Med 2008;358:2560-2572.

8 Scirica BM, Bhatt DL, Braunwald E, Steg PG, Davidson J, Hirshberg B, et al: Saxagliptin and cardiovascular outcomes in patients with type 2 diabetes mellitus. N Engl J Med 2013;369: 1317-1326.

9 Gerstein HC, Miller ME, Byington RP, Goff DC Jr, Bigger JT, Buse JB, et al: Effects of intensive glucose lowering in type 2 diabetes. $\mathrm{N}$ Engl J Med 2008;358:2545-2559.

10 Robertson GL: Thirst and vasopressin function in normal and disordered states of water balance. J Lab Clin Med 1983;101:351371.

11 Russell JA: Vasopressin in septic shock. Crit Care Med 2007;35(9 suppl):S609-S615.

12 Keller T, Tzikas S, Zeller T, Czyz E, Lillpopp L, Ojeda FM, et al: Copeptin improves early diagnosis of acute myocardial infarction. J Am Coll Cardiol 2010;55:2096-2106.

13 Roussel R, Fezeu L, Marre M, Velho G, Fumeron $\mathrm{F}$, Jungers $\mathrm{P}$, et al: Comparison between copeptin and vasopressin in a population from the community and in people with chronic kidney disease. J Clin Endocrinol Metab 2014;99:4656-4663.

14 Stoiser B, Mörtl D, Hülsmann M, Berger R, Struck J, Morgenthaler NG, et al: Copeptin, a fragment of the vasopressin precursor, as a novel predictor of outcome in heart failure. Eur J Clin Invest 2006;36:771-778.

15 Baumann G, Dingman JF: Distribution, blood transport, and degradation of antidiuretic hormone in man. J Clin Invest 1976;57:1109-1116.

16 Struck J, Morgenthaler NG, Bergmann A: Copeptin, a stable peptide derived from the vasopressin precursor, is elevated in serum of sepsis patients. Peptides 2005;26:2500-2504.

17 Langdon-Brown W, Seward C: A case of Cushing's syndrome. Br Med J 1935;2:253-254.
VP, from Regulator to Disease Predictor for Diabetes and Cardiometabolic Risk
Ann Nutr Metab 2016;68(suppl 2):24-28 DOI: $10.1159 / 000446201$ 
18 Fujiwara Y, Hiroyama M, Sanbe A, Aoyagi T, Birumachi J, Yamauchi J, et al: Insulin hypersensitivity in mice lacking the $\mathrm{V} 1 \mathrm{~b}$ vasopressin receptor. J Physiol 2007;584(pt 1):235-244.

19 Tanoue A, Ito S, Honda K, Oshikawa S, Kitagawa Y, Koshimizu TA, et al: The vasopressin $\mathrm{V} 1 \mathrm{~b}$ receptor critically regulates hypothalamic-pituitary-adrenal axis activity under both stress and resting conditions. J Clin Invest 2004;113:302-309.

20 Tatsuno I, Uchida D, Tanaka T, Koide H, Shigeta A, Ichikawa T, et al: Vasopressin responsiveness of subclinical Cushing's syndrome due to ACTH-independent macronodular adrenocortical hyperplasia. Clin Endocrinol (Oxf) 2004;60:192-200.

21 Abu-Basha EA, Yibchok-Anun S, Hsu WH: Glucose dependency of arginine vasopressininduced insulin and glucagon release from the perfused rat pancreas. Metabolism 2002;51: 1184-1190.

22 Keppens S, de Wulf H: The nature of the hepatic receptors involved in vasopressin-induced glycogenolysis. Biochim Biophys Acta 1979;588:63-69.

23 Whitton PD, Rodrigues LM, Hems DA: Stimulation by vasopressin, angiotensin and oxytocin of gluconeogenesis in hepatocyte suspensions. Biochem J 1978;176:893-898.

24 Enhörning S, Wang TJ, Nilsson PM, Almgren P, Hedblad B, Berglund G, et al: Plasma copeptin and the risk of diabetes mellitus. Circulation 2010;121:2102-2108.

25 Abbasi A, Corpeleijn E, Meijer E, Postmus D, Gansevoort RT, Gans RO, et al: Sex differences in the association between plasma copeptin and incident type 2 diabetes: the prevention of renal and vascular endstage disease (PREVEND) study. Diabetologia 2012 55:1963-1970.
26 Wannamethee SG, Welsh P, Papacosta O, Lennon L, Whincup PH, Sattar N: Copeptin, insulin resistance, and risk of incident diabetes in older men. J Clin Endocrinol Metab 2015; 100:3332-3339.

27 Cooper-Dehoff R, Cohen JD, Bakris GL, Messerli FH, Erdine S, Hewkin AC, et al: Predictors of development of diabetes mellitus in patients with coronary artery disease taking antihypertensive medications (findings from the International Verapamil SR-Trandolapril Study [INVEST]). Am J Cardiol 2006;98:890894.

28 Enhörning S, Bankir L, Bouby N, Struck J, Hedblad B, Persson M, et al: Copeptin, a marker of vasopressin, in abdominal obesity, diabetes and microalbuminuria: the prospective Malmö diet and cancer study cardiovascular cohort. Int J Obes (Lond) 2013;37:598603.

29 Enhörning S, Struck J, Wirfält E, Hedblad B, Morgenthaler NG, Melander O: Plasma copeptin, a unifying factor behind the metabolic syndrome. J Clin Endocrinol Metab 2011; 96:E1065-E1072.

30 Saleem U, Khaleghi M, Morgenthaler NG, Bergmann A, Struck J, Mosley TH Jr, et al: Plasma carboxy-terminal provasopressin ( $\mathrm{co}^{-}$ peptin): a novel marker of insulin resistance and metabolic syndrome. J Clin Endocrinol Metab 2009;94:2558-2564.

31 Enhörning S, Hedblad B, Nilsson PM, Engström G, Melander O: Copeptin is an independent predictor of diabetic heart disease and death. Am Heart J 2015;169:549-556.e1.

32 Riphagen IJ, Boertien WE, Alkhalaf A, Kleefstra N, Gansevoort RT, Groenier KH, et al: Copeptin, a surrogate marker for arginine vasopressin, is associated with cardiovascular and all-cause mortality in patients with type 2 diabetes (ZODIAC-31). Diabetes Care 2013; 36:3201-3207.
33 Tasevska I, Enhörning S, Persson M, Nilsson PM, Melander O: Copeptin predicts coronary artery disease cardiovascular and total mortality. Heart 2016;102:127-132.

34 Fenske W, Störk S, Blechschmidt A, Maier SG, Morgenthaler NG, Allolio B: Copeptin in the differential diagnosis of hyponatremia. J Clin Endocrinol Metab 2009;94:123129

35 Chan J, Knutsen SF, Blix GG, Lee JW, Fraser GE: Water, other fluids, and fatal coronary heart disease: the Adventist health study. Am J Epidemiol 2002;155:827-833.

36 Dennis EA, Dengo AL, Comber DL, Flack KD, Savla J, Davy KP, et al: Water consumption increases weight loss during a hypocaloric diet intervention in middle-aged and older adults. Obesity (Silver Spring) 2010;18:300307.

37 Roussel R, Fezeu L, Bouby N, Balkau B, Lantieri O, Alhenc-Gelas F, et al: Low water intake and risk for new-onset hyperglycemia. Diabetes Care 2011;34:2551-2554.

38 Stookey JD, Constant F, Popkin BM, Gardner $\mathrm{CD}$ : Drinking water is associated with weight loss in overweight dieting women independent of diet and activity. Obesity (Silver Spring) 2008;16:2481-2488.

39 Ferreira-Pêgo C, Guelinckx I, Moreno LA, Kavouras SA, Gandy J, Martinez H, et al: Total fluid intake and its determinants: crosssectional surveys among adults in 13 countries worldwide. Eur J Nutr 2015;54(suppl 2):35-43.

40 Taveau C, Chollet C, Waeckel L, Desposito D, Bichet DG, Arthus MF, et al: Vasopressin and hydration play a major role in the development of glucose intolerance and hepatic steatosis in obese rats. Diabetologia 2015;58: 1081-1090. 